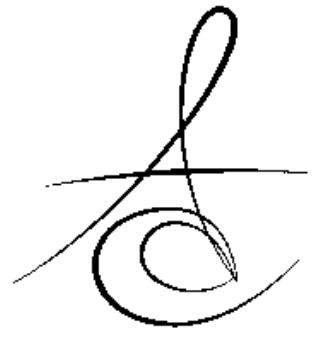

\title{
ONE SHAPE NEW GENERATION, K3XF, TWİSTED FİLE ADAPTİF VE PROTAPER NEXT ENSTRÜMANTASYON SİSTEMLERİ KULLANIMI SONRASI KÖK DENTİNİN EĞİLME DAYANIMI
}

\section{FLEXURAL STRENGHT OF ROOT DENTIN AFTER ROOT CANAL PREPARATION USING ONE-SHAPE NEW GENERATION, $\mathrm{K}^{\mathrm{Tm}} \mathrm{XF}$, TWISTED FILE ADAPTIVE, AND PROTAPER NEXT INSTRUMENTATION SYSTEMS}

\author{
Yrd. Doç.Dr. Recai ZAN* \\ Doç. Dr.Kerem Engin AKPINAR* \\ Prof. Dr. İhsan HUBBEZOGLU* \\ Dr.Zuhal MUTLU*
}

Makale Kodu/Article code: 2556

Makale Gönderilme tarihi; 18.01 .2016

Kabul Tarihi: 26.04.2016

\section{öz}

Amaç: Çeşitli döner nikel-titanyum enstrümantasyon sistemlerinin kullanımı sonrası kök dentini eğilme dayanımının değerlendirilmesi.

Yöntem: Seksen adet çekilmiş tek köklü insan alt çene küçükazı dişi kullanıldı. Başlangıçta, giriş kaviteleri hazırlandı ve 10 no'lu $\mathrm{K}$ tipi eğe apikal foramenden görününceye kadar kanala yerleştirildi ve çalışma uzunluğu (WL) bu uzunluktan $1 \mathrm{~mm}$ kısa olacak şekilde belirlendi. Aynı uzunluk ve kalınlıklarda standardize edillen kök kanalları One Shape New Generation (OSNG), K3XF, Twisted File Adaptif (TFA) ve Protaper Next (PTN) ) sistemleri kullanılarak kök kanalları şekillendirildi. Örnekler üç-noktalı eğilme testine maruz bırakıldı. Elde edilen veriler, tek yönlü varyans analizi (ANOVA) ve Tukey's post-hoc testleri kullanılarak analiz edildi.

Bulgular: TFA grubu tüm diğer gruplarla kıyaslandığında istatistiksel olarak daha yüksek eğilme dayanımı değerleri sağladı $(p<0,05)$. PTN enstrümanları ile şekillendirme sonrası oluşan kök dentini eğilme dayanımı değerleri, TFA grubuna göre istatistiksel olarak daha düşük bulundu $(p<0,05)$. En düşük eğilme dayanımı değerleri OSNG ile K3XF gruplarında görülürken, bu gruplar arasında istatistiksel olarak anlamlı bir fark görülmedi $(p>0,05)$.

Sonuçlar: Bu çalışmanın koşulları altında, tüm nikeltitanyum döner enstrumantasyon sistemlerinin kulanı$\mathrm{mı}$, kök dentininin zayıflamasına ve eğilme dayanımının düşmesine neden olmuştur. Özellikle, OSNG ve K3XF enstrümanları kök dentininin eğilme dayanımının yüksek oranda düşüşüne neden olmuşlardır.

Anahtar kelimeler: Eğilme dayanımı, NiTi enstrümantasyon sistemleri, kök dentini

\section{ABSTRACT}

Aim: To assess the flexural strength of root dentin after using various rotary nickel-titanium instrumentation systems.

Method: Eighty extracted single-rooted human mandibular premolar teeth were used. Initially, access cavities were prepared and a size $10 \mathrm{~K}$-file was placed into the canal until it was visible at the apical foramen, and the working length (WL) was established $1 \mathrm{~mm}$ short of this length. The root canals, which standardized in the same length and thicknesses, were prepared using One Shape New Generation (OSNG), K3XF, Twisted File Adaptive (TFA) and ProTaper Next (PTN) instruments. The samples were exposed a three-point bending test. The data obtained were analyzed using the one-way analysis of variance (ANOVA) and Tukey post-hoc tests.

Results: The TFA group provided statistical higher values compared to all other groups $(p<0.05)$. The flexural strength of root dentin formed after PTN group was significantly lower than TFA group $(p<0.05)$. Although the lowest flexural strength values were detected in OSNG and K3XFgroups, there was no significant difference between the OSNG and K3XF ( $p>0.05)$.

Conclusions: Under the conditions of this study, all instrumentation systems caused the weakening of root dentin and thus reduction of the flexural strength. Specially, OSNG and K3XF instruments caused the least flexural strength value on root dentin.

Key words: Flexural strength, NiTi instrumentation systems, root dentin

* Cumhuriyet Üniversitesi, Diş Hekimliği Fakültesi, Endodonti AD

** Cumhuriyet Üniversitesi, Diş Hekimliği Fakültesi, Restoratif Diş Tedavisi AD 


\section{GİRIŞ̧}

Kök kanal tedavilerinde başarı; doğru teşhis, kök kanallarının etkin bir şekilde temizlenmesi, şekillendirilmesi, dezenfeksiyonu ve sıkı bir tıkama sağlayacak biçimde doldurulmasına bağlıdır. ${ }^{1}$ Ancak kemomekanik preparasyon esnasında kanalın orjinal şeklinin bozulması, basamak oluşumu, perforasyonlar, apikal zip oluşumu gibi istenmeyen durumlar meydana gelmektedir. $^{2}$ Kanal tedavileri sırasında yapılan bu preparasyon sonucunda dişin elastikiyetinin ve kırılma direncini azalması gibi kök dentin yapısında bozulmalar gözlemlenebilmektedir. ${ }^{3} \mathrm{Bu}$ istenmeyen durumun öne çıkan nedenlerini kanal tedavisi sırasında kök-kanal sisteminde meydana gelen madde kayıpları, endodontik giriş kavitesi hazırlığı ve dişte ciddi zayıflamalara neden olan derin mine ve dentin çürükleri şeklinde sıralayabiliriz. ${ }^{4,5}$ Yapılan bazı çalışmalar kök kanal tedavisi yapılmış dişlerde meydana gelen kırılmaların dişin dentin yapısında oluşan değişiklere bağlı olarak oluşabileceği gösterilmiştir. ${ }^{6,7}$ Kök kanal preparasyonunda özellikle son zamanlarda oldukça popüler hale gelen ve araştırıcılar tarafından farklı özellikleri ortaya $\operatorname{konan}^{8,9}$ nikel titanyum (Ni-Ti) eğelerde fleksibilite nedeniyle kanallarda zipping, basamak ve perforasyon oluşturma eğilimini azaltmasına rağmen, $\mathrm{Ni}$-Ti eğelere ön eğim verilememesi ve yenilenen yüzey şekilleri nedeniyle kök dentininde zayıflamalara yol açabilmektedir. Bıçak dizaynı, uç konfigürasyonu ve hareket etme şekilleri açısından birbirlerinden farklı olan kanal şekillendirme sistemleri, çeşitli derecelerde kanal duvarına zarar verebilirler. ${ }^{10}$ Kim ve ark. ${ }^{11} \mathrm{NiTi}$ döner alet kullanımı ve kök kırığı oluşumu arasında potansiyel bir ilişki bulmuşlardır ve eğe tasarımının, apikal stresi ve burkulma konsantrasyonunu etkilediğini öne sürmüşlerdir.

PTN'in (PTN; Dentsply Maillefer, Ballaigues, Switzerland) asimetrik dikdörtgen kesiti, enstrümanın kök kanalı boyunca ilerlerken yılan-benzeri "kıvrılma" hareketi yapmasını sağlar. Asimetrik kesitin dönüşü debrisin taşınması için daha geniş bir alan yaratır. Üretici firma PTN' in yılana benzer hareket etkisi sayesinde kanal yolunun takibinin optimum seviyede olduğunu belirtmektedir. Twisted File Adaptive (TFA; SybronEndo, Orange, CA) aralıksız rotasyon ve ileri geri hareketlerle kombine kullanan yeni bir eğe sistemidir. Eğeler devamlı rotasyonda kullanılırken minimal seviyede veya hiç güç uygulanmadan kullanılmakta iken, eğelerin ileri geri hareketleri sırasında belirli bir güç uygulanmaktadır. ${ }^{12}$ Üretici firma R-fazda kullanılan adaptif teknoloji ve burgulu eğe tasarımı debrisin kök kanallarından uzaklaştırılmasını ve esnekliği arttırdığını belirtmiştir. Aynı zamanda eğenin kanal içerisinde bükülme kuvvetlerine göre şekil almasına müsade etmektedir.

K3 ${ }^{\text {TM } X F ~(S y b r o n E n d o, ~ O r a n g e, ~ C A), ~ K 3 ~ e n s t-~}$ rüman sisteminin bir sonraki nesli olarak nitelendirilebilir. Üretici firmalar $\mathrm{K}^{\mathrm{TM}}{ }^{\mathrm{M}} \mathrm{XF}$ 'in klinisyenlere R-faz teknolojisi ile yeni seviyede döngüsel yorgunluk esneklik ve direnç sağladığını idda etmektedirler. OneShape (OSNG; MicroMega, Besancon, France) geleneksel, devamlı ve dönme hareketiyle kullanılan bir başka yeni eğe sistemidir. OSNG kök kanalının her üç bölgesinde de optimal ve daha iyi bir kesim sağlayan asimetrik enine kesit geometrisine sahip bir sistemdir. Literatürde K3XF ve OSNG NiTi eğe sistemleri ile yapılan preparasyonun kök dentininin travmalara karşı direncine etkisini daha önce inceleyen herhangi bir araştırma bulunmamaktadır. Bu bilgiler ışı̆̆ında araştırmamızda çeşitli yeni jenerasyon döner nikel-titanyum enstrümantasyon sistemlerinin kullanımı sonrası kök dentini eğilme dayanımının değerlendirilmesini amaçladık.

\section{GEREÇ VE YÖNTEM}

Seksen adet çekilmiş tek kök tek kanallı mandibular alt küçük azı dişleri kullanıldı. Tüm dişlerden mezio-distal ve bukko-lingual yönde periapikal radyografiler alınarak, kök kanal kalsifikasyonu tespit edilen, birden fazla kanalı olan ve foramen apikale gelişimini tamamlamamış olan dişler çalışmaya dâhil edilmedi. Başlangıçta, giriş kaviteleri hazırlandı ve 10 no'lu K tipi eğe apikal foramenden görününceye kadar kanala yerleştirildi ve çalışma uzunluğu (WL) bu uzunluktan $1 \mathrm{~mm}$ kısa olacak şekilde belirlendi. Dişlerin kök yüzeyleri erimiş mum ile kaplandı. Mum soğuduktan sonra dişler akrilik rezin içerisine gömüldü. Akrilik rezin sertleştikten sonra dişler çıkarıldı ve üzerindeki mumlar ve soket sıcak su yardımıyla temizlendi. Daha sonra soket polieter ölçü materyali (Impregum Penta Soft Quick Step, 3M ESPE) ile doldurulup, dişler yeniden sokete yerleştirilerek periodontal ligament taklit edildi ve taşan ölçü materyali bistürü yardımıyla uzaklaştırıldı. ${ }^{13}$ Preparasyon işlemleri öncesinde sürgülü kumpas ile yapılan ölçümler ile aynı uzunluk ve kalınlıklarda standardize edilen kök kanalları rastgele olarak 4 gruba ayrıldı $(n=20)$.

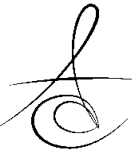




\section{OSNG Grubu}

Kanal preparasyonu OSNG Ni-Ti döner eğe sistemi ile $400 \mathrm{rpm}$ hızda, $2 \mathrm{Ncm}$ tork değerindeki elektrikli motor kullanılarak yapıldı. Kanallar 0,06 açılı \#25 eğe ile çalışma boyunda ve dengeli kuvvetle şekillendirme prosedürü kullanılarak şekillendirildi.

\section{K3XF Grubu}

Kanal preparasyonu K3XF $\mathrm{Ni}-\mathrm{Ti}$ döner eğe sistemi ile $400 \mathrm{rpm}$ hızda, $2 \mathrm{Ncm}$ tork değerindeki Sybron (SybronEndo, Orange, CA) elektrikli motor kullanılarak yapıldı. Kök kanal giriş eğesi eğesi olarak 0,10 açlı \#25 eğe çalışma boyunun yarısına kadar kullanılırken, 0,04 açılı \#25, 0,06 \#25 'lik eğeler çalışma boyunda kullanıldı.

\section{TFA Grubu}

TFA NiTi döner eğeleri, tork kontrollü TFA programlı motor (SybronEndo, Orange, CA) kullanılarak uygulandı. Kök kanal şekillendirilmesi 0,08 açılı \#25 eğe (ML1 programı) çalışma boyunda kullanılarak tamamlandı.

\section{PTN Grubu}

PTN enstrümanları 300 rpm'lik bir hızda sabit bir rotasyonda düşük apikal basınç ile kullanııldı. Optimum bir kullanım için, tork kontrol cihazı $2.0 \mathrm{Ncm}$ olarak ayarlandı. Enstrümanlar kök kanal uzunluğunda X1 (0,4 açlı \#17 eğe) ve X2 (0,6 açlı \#26 eğe) dizisi şeklinde kullanıldı.

OSNG, K3XF, TFA ve PTN NiTi eğe sistemleri ile prepare edilen örnekler Universal test cihazı (LF Plus, LLOYD, Instrument, Ametek Inc, England) ile üç-notalı eğilme testine maruz bırakııdı. Üç noktalı eğilme testi, eğe sistemleri ile yapılan preparasyonu sonra- sında bir ElectroForce 3200 aygitı (Bose, EnduraTEC Sistemler Grubu, Minnetonka, MN, ABD) kullanılarak gerçekleştirilmiştir. Cihazın (H5K-S, Haunsfield Tensometer, Haunsfield Test Equipment Ltd, Redhill, England) hızı $5 \mathrm{~mm} /$ dak olacak şekilde ayarlandı. Yükleme aralarında $10 \mathrm{~mm}$ mesafe bulunan $2 \mathrm{~mm}$ çaplı paralel çubuk destekler üzerine konan numuneye, yine bunlara paralel ve merkezi ekseni tam ortada bulunan $2 \mathrm{~mm}$ çaplı üçüncü bir çubuk vasıtası ile yapıldı. Örneklere standartlarda belirtildiği gibi $50+/-16 \mathrm{~N} / \mathrm{dk}$ yük kırılma anına kadar uygulanmıştır. Örnekler kırıldığı anda cihazın uyguladığı kuvvet bilgisayar ortamına kaydedilerek standartlarda açıklanan formülle hesaplandı Kırılma kuvveti "newton" (N) cinsinden kaydedildi. Transvers direnç ve elastikiyet modülü değerleri aşağıdaki formüllerle hesaplandı.

$$
T S=\frac{3 F I}{2 b h^{2}} \quad E=\frac{I^{3} F}{2 b h^{3} d}
$$

Formüllerde $\mathrm{F}$ kırılma öncesi uygulanan maksimum yük $(\mathrm{N})$, I destekler arası mesafe $(10 \mathrm{~mm}), \mathrm{b}$ test örneklerinin genişliği $(10 \mathrm{~mm}), \mathrm{h}$ test örneklerinin kalınlığı $(2.5 \mathrm{~mm})$, d yük karşııındaki eğilmedir $(\mathrm{mm})$. Daha sonra ölçülen mikrogerilim bağlanma dayanım değerlerinin birimleri Newton cinsinden "megapaskala" (MPa) dönüştürülerek, elde edilen test sonuçları, tek yönlü varyans analizi (ANOVA) ve Tukey's post-hoc testleri kullanılarak analiz edildi

\section{Sonuçlar}

TFA grubu tüm diğer gruplarla kıyaslandığında istatistiksel olarak daha yüksek değerler sağladı $(p<0,05)$. PTN grubu sonrasında oluşan kök dentini eğilme dayanımı TFA grubuna göre istatistiksel olarak daha düşük değerler sağladı $(p<0,05)$. En düşük eğilme dayanımına neden olan grupların OSNG ve K3XF grupları olduğu görülürken, OSNG ile K3XF arasında istatistiksel olarak anlamlı bir fark bulunmadı $(p>0,05)$.

Table 1. Tüm gruplara ait Ortalama (Standart Sapma), minimum ve maximum değerler ile istatistiksel karşılaştırmalar

\begin{tabular}{|c|c|c|c|}
\hline Gruplar & $\begin{array}{c}\text { Ortalama (SP) } \\
\text { (MPa) }\end{array}$ & $\underset{(\mathrm{MPa})}{\operatorname{Minimum}}$ & $\begin{array}{c}\text { Maximum } \\
(\mathrm{MPa})\end{array}$ \\
\hline $\begin{array}{l}\text { Grup } 1 \text { One-Shape New } \\
\text { Generation }\end{array}$ & $705,20(101,68)^{a}$ & 540 & 856 \\
\hline Grup $2 K 3^{I m} X F$ & $688,80(119,32)^{a}$ & 530 & 890 \\
\hline $\begin{array}{l}\text { Grup } \mathbf{3} \text { Twisted File } \\
\text { Adaptive }\end{array}$ & $368,10(58,36)^{b}$ & 270 & 450 \\
\hline Grup 4 ProTaper Next & $494,40(97,54)^{\mathrm{c}}$ & 320 & 650 \\
\hline
\end{tabular}

$F=28,010 ; P=0,000(p<0,05)$.

Aynı üst simge ile gösterilen harfler istatistiksel olarak fark olmayan grupları belirtmektedir $(p>0,05)$.

\section{TARTIŞMA}

Endodontik tedavilerde kök kırı̆ı çok sık karşılaşıan bir durum olmasa da dişi çekime götüren önemli olayların başında gelmektedir. Özellikle preparasyon esnasında kullanılan eğeleme sistemlerinin kök kanallarında dişin eğilme dayanımı üzerine yarattıkları farklı etkiler kök kırı̆ı oluşumu riskini arttırabilmektedir. ${ }^{14}$ Eğilme dayanımı, bir materyale uygulanan eğme gerilimleri karşısında kütlenin gösterdiği direnç olarak tanımlanır. ${ }^{15}$ Bizim çalışmamızda da kullandığımız eğilme dayanıklı̆ı̆ı (flexural strenght) testi, ISO

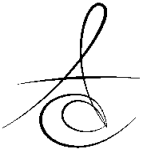


4049(2000) standartlarına göre üç nokta eğme testi şeklinde yapılmaktadır ve three point bending test olarak da tanımlanır. ${ }^{11}$ Bu testte uygulanan kuvvet, örnekte gerilim, basma, makaslama streslerine neden olur. Materyal kırıldığı anda uygulanan kuvvetin miktarı ölçülerek kırılma dayanımı bulunur. Bu test, genellikle kırılgan dental materyaller için tercih edilir. Çünkü bu materyallerin ağız içinde karşılaştığı streslere yakın etkiler oluşur. ${ }^{15,16}$

Endodontik kökenli dikey kök kırığı nadir bir olay olmasına rağmen bunun sonucunda meydana gelebilecek diş kaybı gerçekten önemli bir husustur. Dişlerin kök kırılması yatkınlığı ile ilgili faktörler kapsamlı olarak incelenmiştir. Ancak hala tartışmalı ve sonuç alınamayan bir konu olarak kabul edilir. Dikey kök kırıkları da NiTi eğelerin farklı şekillendirme özelliklerine ${ }^{11}$ bağlı olarak son kanal şekillendirilmesi sırasında kök kanal yüzeyleri boyunca ortaya çıkan stres konsantrasyonlarından, kanal genişleme derecesinden veya kanal yüzeyleri boyunca görülebilen düzensizlik ya da defektlerden kaynaklanabilir. Kök kanal preparasyonunun, kırıklar ve çatlaklar gibi ciddi dentin defektleri yarattığı rapor edilmiştir. ${ }^{16}$ Iki faktör endodontik tedavi sırasında dikey kök kırığı gelişmesine neden olabilir; Birincisi, özellikle kavisli kökleri veya oval kanalları olan dişlerde yapılan aşırı kanal preparasyonu ve ikincisi giriş kavitesi hazırlanırken diş yapısının aşırı kaldırması sonucu dişin genel yapısının zayıflaması. ${ }^{17}$ Preparasyon, kanal duvarları ile enstrümanlar arasındaki kontaklar ile gerçekleşmektedir. Bu kontaklar dentin yüzeyinde birçok anlık stres konsantrasyonları oluşturabilmektedir. Bu tip stres konsantrasyonları dentin hasarlarına yol açarak dikey kök kırıklarının oluşmasına neden olabilir. Enstrümantasyon sırasında kök yüzeyindeki yüksek gerilmelerin dentin hasarlarında artışa sebebiyet vermesi ve böylece dikey kök kırık riskini artırması beklenebilir. ${ }^{18}$ Dentin çatlağı ve kök kırıkları, kök kanallarının mekanik preparasyonu sonucu meydana gelebilen ve dişin kaybıyla sonuçlanabilen komplikasyonlar arasındadır.

Endodontik olarak tedavi görmüş dişlerin dayanıklılığı direkt olarak kök kanalı preparasyon tekniğine ve geride kalan sağlıklı diş yapısına bağlıdır. Dentin kaybındaki artışın kırılma riskini artıracağı bilinen bir gerçektir. ${ }^{19}$ Vertikal kök kırığı en çok endodontik tedavi görmüş dişlerde gözlendiği ortaya konmuştur. ${ }^{20}$ Dişlerin kırma direnci inceleyen çalışmalar genelde kanalın konisitesini ${ }^{21}$, post yerleştirilmesinin etkisini ${ }^{22}$, kanal dolgu patlarının veya doldurma yöntemlerinin etkisi$\mathrm{ni}^{23}$, kanal doldururken kullanılan spreader'ın numara$\operatorname{sını}^{24}$, farklı restorasyon maddelerinin etkisini ${ }^{25}$ ve kalsiyum hidroksit kullanılmasının etkisini incelemiştir ${ }^{26}$, literatürde sadece kanal genişletme prosedürlerinin dişlerin kırılma direncine etkisini inceleyen çok az çalışma mevcuttur. ${ }^{27}$

Biz ise çalışmamızda sadece farklı kanal genişletme prosedürlerinin etkisini incelemek istedik. Böylece sistemlerin oluşturduğu defekt/çatlak miktarı ile dişlerin kırımaya direnci arasındaki ilişkinin tutarlı olup olmadığını incelemeyi amaçladık.

Protaper Next enstrümanları, nispeten yeni geliştirilmiş bir sistemdir. Enstrümanlar asimetrik dikdörtgen kesite, değişken gerileyen tapera ve özel asimetrik yılan benzeri (snake-like swaggering movement) dönme hareketine sahiptirler. Ayrıca ısıl işlem prosesi olan M-Wire teknolojisiyle üretilmişlerdir. Bu özellikler ile enstürman ve kanal duvarları arasında temas noktalarının OSNG ve K3XF rotary sitemlerine kıyasla daha az olması, TFA ile preparasyon sonucu oluşan kök dentin dayanımının bu sistemlere göre daha yüksek olmasına neden olmuş olabilir. ${ }^{28}$

OSNG enstürmanı üçgensel çapraz kesit geometrisine sahipken, Protaper Next enstümanı dörtgensel kesite sahiptir. Ancak OSNG enstrümanı geleneksel $\mathrm{NiTi}$ alaşımından üretilmesine rağmen PTN enstrümanı M-wire ısıl işlem prosesi ile üretilmektedir. Johnson ve ark. ${ }^{29}$ yaptıkları çalışmada, 508 nitinol ve M-wire ısıl işlem prosesi ile üretilen enstürmanları karşılaştırmışlar ve M-wire teknolojisiyle üretilen enstürmanları, diğer enstrümanlara göre $390 \%$ dan daha fazla fleksural yorgunluğa karşı dirençli bulmuşlardır. Yaptığımız çalışmada da M-wire ısıl işlem prosesiyle üretilen enstürmanı ile preparasyon sonucu oluşan kök dentin dayanımının, geleneksel NiTi alaşım olan OSNG enstürmanı ile preparasyon sonucu oluşan kök dentin dayanımından daha yüksek bulunmasının, enstürmanların farklı metalürjik karakterlere sahip olduğundan dolayı olmuş olabilir.

TF enstürmanı 2008 yılında, ısıl işlem (R faz), metal telin bükülmesi ve özel yüzey işlemlerini içeren üç proses sonucunda üretilmiştir. ${ }^{30}$ Çalışmamızda kullandığımız bir diğer enstürman olan K3XF enstürmanı da, aynı R-Phase ısı ve soğutma protokolü ile üretilmesine rağmen, TFA enstürmanı gibi bükülme işlemi yerine tornada kesilme işlemiyle üretilmektedir. ${ }^{31}$ TF enstürmanı trianguler üçgen kesite sahipken, 
K3XF enstürmanı, üçlü U şekilli çapraz kesite ve 3 adet radyal alana sahiptir. ${ }^{32}$ Çalışmamızın sonucunda TFA enstürmanın K3XF enstrümanına göre preparasyon sonrası oluşan kök dentin dayanımın yüksek olmasını, enstürmanların sahip olduğu farklı çapraz kesit dizaynları ve üretim aşamasındaki burulma ve tornada kesilerek üretilmelerindeki farklılıklardan kaynaklanabileceğini düşünmekteyiz.

Hareket kinematiği de (devamlı rotasyon veya reciprokasyon hareketi) enstrümanların fleksural yorgunluğa karşı direncini etkileyen faktörlerden bir tanesidir. Resiprokasyon hareketi; devamlı rotasyon hareketiyle karşılaştırıldığında, enstürmanların üzerinde oluşan flkesural yorgunluğu ve enstrümanın kök dentininde oluşturduğu apikal stresi etkileyebilmektedir. ${ }^{32,33}$ Resiprokasyon hareketi ile kullanılan enstürmanlar, daha kısa açısal mesafe kat etmekte, sonucunda metal yorgunluğuna karşı dirençleri artmaktadır. ${ }^{34}$ Çalışmamızda kullanılan PTN, K3XF ve OSNG enstürmanları devamlı rotasyon hareketiyle kullanılmasına rağmen, TFA enstürmanı, rotasyon ve resiprokasyon hareketlerini kombine gerçekleştiren, adaptif hareket ile çalışan tek enstrüman grubumuzdur. Çalışmamızın sonucunda, TFA enstürman grubunun, preparasyon sonrası oluşturduğu kök dentin dayanımının, diğer tüm enstrüman gruplarının preparasyon sonrası oluşturdukları kök dentin dayanımından fazla olmasını, enstrümanların farklı kullanım kinematiklerinden dolayı olabileceğini düşünmekteyiz.

Kırma Testi sonuçları incelendiğinde aralarında istatistiksel olarak anlamlı bir fark bulunmasa da kök dentininde en düşük direncin oluşmasına neden olan sistemlerin sırasıyla, K3XF ve One-Shape New Generation grupları iken bunları ProTaper Next grubu izlemiştir. En yüksek direnci sağlayan grup ise Twisted File Adaptive grubu olduğu gözlenmektedir. Çalışmamızda kırılma dayanımı testi ile elde ettiğimiz bulgular sonucu, çalışma grupları arasında en düşük kırılma direnci değerlerini gösteren K3XF ve OneShape New Generation NiTi sistemlerinin genişletme esnasında oluşturdukları çatlakların dişin kırılmaya karşı direncini düşürdüğü düşünmekteyiz.

\section{SONUÇ}

Bu çalışmanın koşulları altında, tüm Nikel-titanyum döner enstrumantasyon sistemleri preparasyon sırasında kök dentininin zayıflamasına ve bunun sonucunda eğilme dayanımı seviyesinin düşmesine neden olmuştur. Özellikle, OSNG ve K3XF döner enstrumantasyon sistemleri, kök kanal preparasyonu sonucu dişlerin kırılmalara karşı daha dirençsiz hale gelmelerine neden olmuşlardır.

\section{KAYNAKLAR}

1. Deplazes P, Peters O, Barbakow F. Comparing apical preparations of root canals shaped by nickel-titanium rotary instruments and nickel-titanium hand instruments. J Endod 2001;27:196-202.

2. Sonntag D, Guntermann A, Kim SK, Stachniss V. Root canal shaping with manual stainless steel files and rotary $\mathrm{Ni}-\mathrm{Ti}$ files performed by students. Int Endod J 2003;36:246-55.

3. Reeh ES, Messer HH, Douglas WH. Reduction in Tooth Stiffness as a Result of Endodontic and Restorative Procedures. J Endod 1989;15:512-6.

4. Assif D, Gorfil C. Biomechanical considerations in restoring endodontically treated teeth. J Prosthet Dent 1994;71:565-7.

5. Gonzalez-Lopez S, De Haro-Gasquet F, Vilchez-Diaz MA, Ceballos L, Bravo M. Effect of restorative procedures and occlusal loading on cuspal deflection. Oper Dent 2006;31:33-8.

6. el-Sherif $M H$, Halhoul MN, Kamar AA, Nour el-Din A. Fracture strength of premolars with Class 2 silver amalgam restorations. Oper Dent 1988;13:50-3.

7. Mondelli J, Steagall L, Ishikiriama A, de Lima Navarro MF, Soares FB. Fracture strength of human teeth with cavity preparations. J Prosthet Dent 1980;43:419-22.

8. Evren O, Hüseyin E, Banu U. Kök kanalında kırılmış döner aletlerin kök kanalının apikal mikrosızıntısı üzerine etkisi. Ondokuz Mayis Univ Dis Hekim Fak Derg. 2014;2:85-90.

9. Tamer T. Tolga C. Üç Farkli Döner Alet Tekniğinin Apikalden İtilen Yikama Solüsyonu Ve Debris Yönünden Karşilaştirilmasi. Ondokuz Mayis Univ Dis Hekim Fak Derg 2006;2:33-36.

10. Shemesh H, Bier CAS, Wu M-K. The effects of canal preparation and filling on the incidence of dentinal defects. Int Endod J 2009;42;208-13.

11. Kim Hyeon-Cheol, Lee Min-Ho. Potential Relationship between Design of Nickel-Titanium Rotary Instruments and Vertical Root Fracture. J Endod 2010;36:1195-9.

12. Gergi R, Arbab-Chirani R, Osta N, Naaman A. Microcomputed tomographic evaluation of canal transportation instrumented by different kinematics

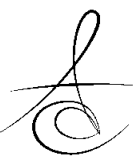


rotary nickel-titanium instruments. J Endod 2014;40:1223-7.

13. Shemesh $H$, Bier CAS, Wu M-K. The effects of canal preparation and filling on the incidence of dentinal defects. Int Endod J 2009;42:208-13.

14. Bier CA, Shemesh $H$, Tanomaru-Filho $M$, et al. The ability of different nickel- titanium rotary instruments to induce dentinal damage during canal preparation. J Endod 2009;35: 236-8.

15. Anusavıce, K.J. Phıllıps Science of Dental Materials. 11th Ed. Missouri: Saunders, 2003. Chapter 4.

16. Ortengren, U. Elgh, U. Spasenoska, V. Mılledıng, P. Haasum, J. Karlsson, S. Water sorption and flexural properties of a composite resin cement. Int J Prosthodont 2000;13:141-7.

17. Ali, C..Y. Ahmet, U.G. Ebru, Ö. Simüle Eğri Kanallarda Farklı Kök Kanal Dolgu Tekniklerinin Karşılaştırılması. Ondokuz Mayis Univ Dis Hekim Fak Derg 2007;8:8590.

18. Kim Hyeon-Cheol, Lee Min-Ho. Potential Relationship between Design of Nickel-Titanium Rotary Instruments and Vertical Root Fracture. J Endod 2010;36:1195-1199.

19. Teíxeira FB, Teixeira ECN, Thompson JY, Trope M. Fracture resistance of roots endodontically treated with a new resin filling material. JADA 2004;135:646-52.

20. Bender IB, Freeland JB.Adult root fracture. JADA 1983;107:413-9.

21. Zandbiglari $T$, Davids $H$, Schäfer $E$. Influence of instrument taper on the resistance to fracture of endodontically treated roots. Oral Surg Oral Med Oral Pathol Oral Radiol Endod 2006;101:126-31.

22. Zhou L, Wang Q. Comparison of fracture resistance between cast posts and fiber posts: a meta-analysis of literature. J Endod 2013;39:11-5.

23. Schäfer $E$, Zandbiglari $T$, Schäfer J. İnfluence of resin based adhesive root canal fillings on the resistance to fracture of endodontically treated roots:an in vitro preliminary study. Oral Surg Oral Med Oral Pathol Oral Radiol Endod 2007;103:274-9.

24. Pişkin B, Aydin B, Sarikanat M. The effect of spreader size on fracture resistance of maxillary incisor roots. Int Endod J 2008;41:54-9.

25. Salameh Z, Ounsi HF, Aboushelib MN, Al-Hamdan R, Sadig W, Ferrari M. Effect of different onlay systems on fracture resistance and failure pattern of endodontically treated mandibular molars restored with and without glass fiber posts. Am J Dent 2010;23:81-6.
26. Zarei M, Afkhami F, Malek Poor Z. Fracture resistance of human root dentin exposed to calcium hydroxideintervisit medication at various time periods: an in vitro study. Dent Traumatol 2013;29:156-60.

27. Lam PP, Palamara JE, Messer HH. Fracture strength of tooth roots following canal preparation by hand and rotary instrumentation. J Endod 2005;31:52932.

28. Gagliardi J, Versiani MA, de Sousa-Neto MD, PlazasGarzon A, Basrani B: Evaluation of the Shaping Characteristics of ProTaper Gold, ProTaper NEXT, and ProTaper Universal in Curved Canals. J Endod 2015;41:1718-1724.

29. Johnson E, Lloyd A, Kuttler S, Namerow K. Comparison between a novel nickel-titanium alloy and 508 nitinol on the cyclic fatigue life of ProFile 25/.04 rotary instruments. J Endod 2008;34:1406-9.

30. Larsen CM, Watanabe I, Glickman GN, et al. Cyclic fatigue analysis of a new generationof nickel titanium rotary instruments. J Endod 2009;35:401-3.

31. Plotino G, Costanzo A, Grande NM, et al. Experimental evaluation on the influence of autoclave sterilization on the cyclic fatigue of new nickel-titanium rotary instruments. J Endod 2012;38:222-5.

32. Pérez-Higueras JJ, Arias A, de la Macorra JC. Cyclic fatigue resistance of $\mathrm{K} 3, \mathrm{~K} 3 \mathrm{XF}$, and twisted file nickel-titanium files under continuous rotation or reciprocating motion. J Endod 2013;39:1585-8.

33. Webber J, Machtou P, Perto W, Kuttler S, Ruddle C, West J. The WaveOne single-file reciprocating system. Roots 2011.

34. Castello-Escriva R, Alegre-Domingo T, Faus-Matoses $\mathrm{V}$, Roman-Richon S, Faus-Llacer VJ: In vitro comparison of cyclic fatigue resistance of ProTaper, WaveOne, and Twisted Files. J Endod 2012;38:15214.

\section{Yazışma Adresi:}

Yrd. Doç. Dr. Recai ZAN

Cumhuriyet Üniv, Diş Hek Fak Endodonti AD 58140 Kampüs / SİVAS

Tel: 0 (346) $2191010 / 2701$

Gsm: 0 (546) 4711147

Faks: 0 (346) 2191237

e-mail: drrecaizan@hotmail.com 